\title{
Investigations into the association between polymorphisms in the interleukin-10 gene and risk of early-onset preeclampsia
}

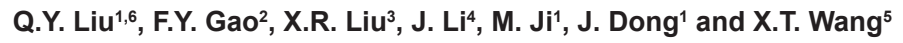 \\ 1Department of Obstetrics, Eighth People's Hospital of Qingdao, Qingdao, China \\ 2Department of Gastroenterology, Qingdao Hiser Medical Group, Qingdao, China \\ ${ }^{3}$ Department of Internal Medicine, Qingdao Women and Children Hospital, \\ Qingdao, China \\ ${ }^{4}$ Department of Obstetrics/Gynaecology, The Affiliated Hospital of Qingdao University, \\ Qingdao, China \\ ${ }^{5}$ Department of Obstetrics/Gynaecology, Shandong Provincial Hospital, Jinan, China \\ ${ }^{6}$ Shandong Provincial Hospital Affiliated to Shandong University, Jinan, China \\ Corresponding author: Q.Y. Liu \\ E-mail: liuqunying2@163.com
}

Genet. Mol. Res. 14 (4): 19323-19328 (2015)

Received August 3, 2015

Accepted October 2, 2015

Published December 29, 2015

DOI http://dx.doi.org/10.4238/2015.December.29.42

ABSTRACT. In this case-control study, we assessed the influence of IL$10-1082 \mathrm{~A} / \mathrm{G}$ and $-819 \mathrm{~T} / \mathrm{C}$ on the development of preeclampsia. The IL$10-1082 \mathrm{~A} / \mathrm{G}$ and $-819 \mathrm{~T} / \mathrm{C}$ polymorphisms were assessed by polymerase chain reaction-restriction fragment length polymorphism. The genotype distributions of the $I L-10-1082 \mathrm{~A} / \mathrm{G}$ and $-819 \mathrm{~T} / \mathrm{C}$ polymorphisms in the control subjects were in conformance with Hardy-Weinberg equilibrium (HWE; $\mathrm{P}=0.46$ and 0.17 ). Unconditional logistic regression analyses revealed that individuals carrying the CC genotype of IL-10 -819T/C were associated with an increased risk of preeclampsia compared to the TT genotype. The odds ratio ( $95 \%$ confidence interval) for the CC genotype of IL-10 -819T/C was 1.71 (1.07-3.27) compared to the TT genotype. 
In conclusion, the results of our study indicated that the $I L-10-819 T / C$ polymorphism was associated with an increased risk of preeclampsia in a Chinese population.

Key words: Interleukin-10; Polymorphism; Early-onset preeclampsia

\section{INTRODUCTION}

Preeclampsia is a multi-system disorder unique to pregnancy, which is characterized by high hypertension and proteinuria above twenty weeks' gestation (Redman and Sargent, 2005; Sibai et al., 2005). This disease would contribute to the preterm birth and intrauterine growth restriction, and increase the risk of perinatal materno-fetal morbidity and mortality. The preeclampsia is involved in many environmental factors, such as preexisting hypertension, diabetes and obesity as well as smoking (Wang et al., 2002; Chelbi et al., 2007). Moreover, many genetic factors also contribute to the development of this disease, such as interleukin (IL)-6, NLRP1 and MTHFR genes (Pontillo et al., 2015; Sowmya et al., 2015; Wu et al., 2015).

Previous studies have reported that altered concentrations of many cytokines may contribute to the defective placental invasion and endothelial damage in preeclampsia. Several previous studies have reported that IL-1 $\beta$, IL-4, IL-1 $\alpha$, and IL-6 (Bayoumy et al., 2013; Chen et al., 2014; Kang et al., 2014; Wang et al., 2014). IL-10 gene has an important role in Th2 immunity, and is located on human chromosome 1 (1q31-1q32) (Kim et al., 1992; Eskdale et al., 1997). Two common single nucleotide polymorphisms (SNPs) in the $I L-10$ gene, such as $-1082 \mathrm{~A} / \mathrm{G}$ and $-819 \mathrm{~T} / \mathrm{C}$, locate regions of the promoter region and regulate the levels of circulating IL-10 (D'Alfonso et al., 2000; Mormann et al., 2004). Several studies have reported the correlation between polymorphisms in the $I L-10$ gene and susceptibility to preeclampsia; however, the results have been inconsistent (Pissetti et al., 2014; Sowmya et al., 2014a,b; Yang et al., 2014). In this case-control study, we conducted a case-control study to assess the influence of $I L-10-1082 \mathrm{~A} / \mathrm{G}$ and $-819 \mathrm{~T} / \mathrm{C}$ in the development of preeclampsia.

\section{MATERIAL AND METHODS}

\section{Patients}

A total of 177 women suffering from preeclampsia above 20 weeks of gestation were enrolled in this case-control study from the Eighth People's Hospital of Qingdao between March 2012 and March 2014. Preeclampsia were defined as gestation more than 20 weeks, blood pressure $\geq 140 / 90 \mathrm{mmHg}$ and presence of proteinuria. Patients with a previous history of intrauterine fetal deaths were excluded from the study. In addition, 182 control subjects at the $>20$ weeks gestation stage were collected at our hospital during the same period. The excluded criteria of the controls were those who had a chronic hypertension or a history of renal, autoimmune, metabolic, or cardiovascular disease.

Demographic and clinical data were collected from a self-designed questionnaire and medical record. Written informed consents were obtained from patients and control subjects prior to the study. The study was previously approved by the Institutional Research Ethics Committee of the Eighth People's Hospital of Qingdao. 


\section{DNA extraction and genotyping}

Two milliliters of peripheral blood was collected from the patients prior to their treatment in EDTA-anticoagulant tubes. Genomic DNA was extracted from the blood, using the QIAamp DNA MAX Kit (Qiagen, Hilden, Germany). The IL-10 -1082A/G and -819T/C polymorphisms were assessed using the polymerase chain reaction restriction fragment length polymorphism (PCRRFLP) assay. The following forward and reverse primers were used in this assay: IL-10 -1082A/G: 5'-TGATACTATCTCGTCTTTGATCG-3' and 5'-TCCGGCTTGTGAATGGCTGA-3'; IL-10 -819T/C: 5'-TGAATGTATGTGCTGGAGATCC-3' and 5'-GGTGAGCGTGCCTTCGGC-3', respectively. The PCR conditions were set as follows: $95^{\circ} \mathrm{C}$ for $5 \mathrm{~min}$ for the initial denaturation, following 30 cycles of denaturation at $95^{\circ} \mathrm{C}$ for $30 \mathrm{~s}$, annealing at $62^{\circ} \mathrm{C}$ for $45 \mathrm{~s}$, extension at $72^{\circ} \mathrm{C}$ for $30 \mathrm{~s}$ and final extension at $72^{\circ} \mathrm{C}$ for $5 \mathrm{~min}$. The PCR products were confirmed via electrophoresis on a $2 \%$ agarose gel stained with ethidium bromide, which was ubsequently visualized under UV light.

\section{Statistical analysis}

The demographic and clinical data were expressed as the mean \pm standard deviation and frequency and percentage. Conformance with the Hardy-Weinberg equilibrium (HWE) was tested using the standard $\chi^{2}$ test or the Fisher exact test. Unconditional logistic regression analysis was used to evaluate the association between $I L-10-1082 A / G$ and $-819 T / C$ polymorphisms and risk of preeclampsia; the results of this analysis were expressed as odds ratio (ORs) and corresponding $95 \%$ confidence intervals $(95 \% \mathrm{Cl})$. A two-tailed $\mathrm{P}$ value $<0.05$ was considered to be statistically significant. All statistical tests were performed on the SPSS 21.0 package (SPSS Inc., Chicago, IL, USA).

\section{RESULTS}

We observed no significant differences in the age of the preeclampsia patients and controls. Preeclampsia patients were more likely to have a higher gestational age, BMI, systolic blood pressure, and diastolic blood pressure, and lower number of weeks up to delivery and undergo Caesarean delivery, compared to the control subjects (Table 1).

\begin{tabular}{|c|c|c|c|c|c|c|}
\hline Variables & Patients $(\mathrm{N}=177)$ & $\%$ & Controls $(\mathrm{N}=182)$ & $\%$ & $t$ or $\chi^{2}$ test & $P$ value \\
\hline Age (years) & $28.20 \pm 4.75$ & & $27.45 \pm 4.96$ & & 1.46 & 0.07 \\
\hline Gestational age (weeks) & $26.46 \pm 3.84$ & & $25.62 \pm 4.10$ & & 2.01 & 0.02 \\
\hline BMI $\left(\mathrm{kg} / \mathrm{m}^{2}\right)$ & $29.51 \pm 4.20$ & & $28.20 \pm 3.95$ & & 3.05 & 0.001 \\
\hline Systolic blood pressure $(\mathrm{mmHg})$ & $148.30 \pm 11.85$ & & $114.23 \pm 12.23$ & & 26.80 & $<0.001$ \\
\hline Diastolic blood pressure $(\mathrm{mmHg})$ & $97.43 \pm 18.40$ & & $70.52 \pm 13.45$ & & 15.85 & $<0.001$ \\
\hline Delivery weeks & $35.65 \pm 3.60$ & & $39.10 \pm 1.42$ & & 12.01 & $<0.001$ \\
\hline \multicolumn{7}{|l|}{ Mode of delivery } \\
\hline Normal & 80.712 & 45.6 & 104.286 & 57.3 & & \\
\hline Caesarean & 96.288 & 54.4 & 77.714 & 42.7 & 12.01 & $<0.001$ \\
\hline
\end{tabular}

The $\chi^{2}$ test revealed no significant differences in the genetic frequencies of $I L-10-1082 \mathrm{~A} / \mathrm{G}$ and $-819 \mathrm{~T} / \mathrm{C}$ between the preeclampsia patients and control subjects. The genotype distributions of the $I L-10-1082 A / G$ and $-819 T / C$ polymorphisms were consistent with the HWE in the controls ( $P$ value for HWE: 0.46 and 0.17 , respectively; Table 2). Moreover, the minor allele frequencies 
(MAFs) of IL-10 -1082A/G and -819T/C polymorphisms were similar to the MAFs of dbSNPs (http:// www.ncbi.nlm.nih.gov/snp/).

\begin{tabular}{|c|c|c|c|c|c|c|c|c|c|}
\hline \multirow[t]{2}{*}{ IL-10 gene } & \multirow[t]{2}{*}{ Patients } & \multirow[t]{2}{*}{$\%$} & \multirow[t]{2}{*}{ Controls } & \multirow[t]{2}{*}{$\%$} & \multirow[t]{2}{*}{$\chi^{2}$ test } & \multirow[t]{2}{*}{$P$ value } & \multirow[t]{2}{*}{$P$ value for $\mathrm{HWE}$} & \multicolumn{2}{|c|}{ Minor allele frequency } \\
\hline & & & & & & & & In controls & In database \\
\hline \multicolumn{10}{|l|}{$-1082 A / G$} \\
\hline AA & 83 & 46.89 & 93 & 51.1 & & & & & \\
\hline AG & 77 & 43.5 & 77 & 42.31 & & & & & \\
\hline GG & 17 & 9.6 & 12 & 6.59 & 1.36 & 0.51 & 0.46 & 0.2775 & 0.2722 \\
\hline \multicolumn{10}{|l|}{$-819 \mathrm{~T} / \mathrm{C}$} \\
\hline TT & 54 & 30.51 & 68 & 37.36 & & & & & \\
\hline TC & 80 & 45.2 & 79 & 43.41 & & & & & \\
\hline CC & 43 & 24.29 & 35 & 19.23 & 2.36 & 0.31 & 0.17 & 0.4093 & 0.4347 \\
\hline
\end{tabular}

HWE = Hardy-Weinberg equilibrium

Unconditional logistic regression analyses indicated that individuals carrying the CC genotype of the $I L-10-819 T / C$ were associated with an increased risk of preeclampsia, compared to those expressing the TT genotype. The OR $(95 \% \mathrm{Cl})$ for the CC genotype of $/ \mathrm{L}-10-819 \mathrm{~T} / \mathrm{C}$ was 1.71 (1.07-3.27) compared to the TT genotype (Table 3). However, the IL-10 -1082A/G polymorphism showed no significant association with the risk of preeclampsia.

\begin{tabular}{|c|c|c|c|c|c|c|}
\hline IL-10 gene & Patients & $\%$ & Controls & $\%$ & OR $(95 \% \mathrm{Cl})^{1}$ & $P$ value \\
\hline \multicolumn{7}{|l|}{$-1082 A / G$} \\
\hline$A A$ & 83 & 46.89 & 93 & 51.1 & Ref. & \\
\hline$A G$ & 77 & 43.5 & 77 & 42.31 & $1.26(0.82-1.89)$ & 0.56 \\
\hline GG & 17 & 9.6 & 12 & 6.59 & $1.66(0.72-4.15)$ & 0.21 \\
\hline$A G+G G$ & 94 & 53.1 & 89 & 48.9 & $1.18(0.77-1.83)$ & 0.43 \\
\hline \multicolumn{7}{|l|}{$-819 T / C$} \\
\hline TT & 54 & 30.51 & 68 & 37.36 & Ref. & \\
\hline TC & 80 & 45.20 & 79 & 43.41 & $1.36(0.77-2.32)$ & 0.26 \\
\hline $\mathrm{CC}$ & 43 & 24.29 & 35 & 19.23 & $1.71(1.07-3.27)$ & 0.09 \\
\hline $\mathrm{TC}+\mathrm{CC}$ & 123 & 69.49 & 114 & 62.64 & $1.36(0.86-2.16)$ & 0.17 \\
\hline
\end{tabular}

${ }^{1}$ Adjusted for age, gestational age, body mass index, systolic blood pressure, diastolic blood pressure, delivery weeks and mode of delivery. $\mathrm{OR}=$ odds ratio; $\mathrm{Cl}=$ confidence interval.

\section{DISCUSSION}

In the present study, we investigated the impact of gene polymorphisms with risk of preeclampsia in a sample of Chinese population. Our findings showed a significant association between. In this study, the CC genotype of IL-10 -819T/C was found to be associated with an increased risk of preeclampsia in a Chinese population.

Previous studies have assessed the correlation between $/ L-10-1082 A / G$ and $-819 T / C$ polymorphisms and the susceptiblity to preeclampsia (Daher et al., 2006; Makris et al., 2006; Mirahmadian et al., 2008; Stonek et al., 2008; de Lima et al., 2009; Vural et al., 2010; Sowmya et al., 2014a,b, 2015). Daher et al. (2006) suggests that $I L-10-1082 A / G$ polymorphism was associated with the risk of preeclampsia. Vural et al. (2010) reported that the AA genotype of $I L-10$ 
-1082A/G had 3.38-fold increased risk of developing preeclampsia compared to the GG genotype. Similarly, Sowmya et al. (2014a) conducted a study in an Indian population, they suggested that the $I L-10-819 T / C$ gene polymorphism could contribute to the risk of preeclampsia. Sowmya et al. (2014b) conducted another study in Indian population, and they reported that IL-10 -819T/C and $-592 \mathrm{~A} / \mathrm{C}$ played an important role in the pathogenesis of early-onset preelampsia. Pissetti et al. (2014) suggested that $I L-10-1082 A / G$ polymorphism was correlated with the development of preeclampsia. However, other studies, such as the one conducted by Stonek et al. (2008), have reported the lack of any association between the $I L-10$ gene polymorphism and risk of preeclampsia. Additionally, de Lima et al. (2009) did not find any significant association between the $I L-10-1082 A / G$ and $-819 T / C$ polymorphisms and the development of preeclampsia. A recent meta-analysis pooled with eleven studies, and it suggests that $I L-10-1082 \mathrm{G} / \mathrm{A},-819 \mathrm{C} / \mathrm{T}$ and -592 C/A polymorphisms are unlikely to be associated with pre-eclampsia (Lee et al., 2014). In our study, we found that the $I L-10-819 T / C$ polymorphism contributes to the development of preeclampsia. Further studies with large sample size are greatly needed to confirm our finding.

We identified three limitations in our study. Firstly, patients with preeclampsia and the control subjects were selected from a single hospital, resulting in a selection bias; that is, these subjects may not be representative of other populations. Secondly, other genetic polymorphisms might have influenced the risk of preeclampsia in addition to $I L-10$ gene. Finally, the sample size is relatively small, which may influence the statistical power of identifying differences between the groups.

In conclusion, the results of our study indicate an association between the IL-10 -819T/C polymorphism and an increased risk of preeclampsia in a Chinese population.

\section{Conflicts of interest}

The authors declare no conflict of interest.

\section{REFERENCES}

Bayoumy NM, Al-Sharaidh AS, Babay ZH, Abdulgader AM (2013). The role of interleukin-6 promoter polymorphism -174G/C in Saudi women with hypertensive disorders of pregnancy. Saudi Med. J. 34: 689-94.

Chelbi ST, Mondon F, Jammes H, Buffat C, et al. (2007). Expressional and epigenetic alterations of placental serine protease inhibitors: SERPINA3 is a potential marker of preeclampsia. Hypertension 49: 76-83.

Chen P, Zhou B, Zhang K, Zhang Z, et al (2014). An insertion-deletion polymorphism in interleukin-1a gene associated with susceptibility to preeclampsia. Hypertens. Pregnancy 33:395-401.

D'Alfonso S, Rampi M, Rolando V, Giordano M, et al. (2000). New polymorphisms in the IL-10 promoter region. Genes Immun. 1: 231-233.

Daher S, Sass N, Oliveira LG and Mattar R (2006). Cytokine genotyping in preeclampsia. Am. J. Reprod. Immunol. 55: $130-135$. de Lima TH, Sass N, Mattar R, Moron AF, et al. (2009). Cytokine gene polymorphisms in preeclampsia and eclampsia. Hypertens. Res. 32: 565-569.

Eskdale J, Kube D, Tesch H (1997). Mapping of the human IL10 gene and further characterization of the $5^{\prime}$ flanking sequence. Immunogenetics 46:120-128.

Kang L, Chen $\mathrm{CH}, \mathrm{Yu} \mathrm{CH}$, Chang $\mathrm{CH}$, et al (2014). An association study of interleukin-4 gene and preeclampsia in Taiwan. Taiwan J. Obstet. Gynecol. 53: 215-219.

Kim JM, Brannan Cl, Copeland NG (1992). Structure of the mouse IL-10 gene and chromosomal localization of the mouse and human genes. J. Immunol. 148: 3618-3623.

Lee YH, Kim JH, Song GG (2014). Meta-analysis of associations between interleukin-10 polymorphisms and susceptibility to pre-eclampsia. Eur. J. Obstet. Gynecol. Reprod. Biol. 182: 202-207.

Makris A, Xu B, Yu B, Thornton C, et al (2006). Placental deficiency of interleukin-10 (IL-10) in preeclampsia and its relationship to an IL10 promoter polymorphism. Placenta 27: 445-451. 
Mirahmadian M, Kalantar F, Heidari G, Safdarian L, et al. (2008). Association of tumor necrosis factor-alpha and interleukin-10 gene polymorphisms in Iranian patients with pre-eclampsia. Am. J. Reprod. Immunol. 60: 179-185.

Mörmann M, Rieth H, Hua TD, Assohou C, et al. (2004). Mosaics of gene variations in the Interleukin-10 gene promoter affect interleukin-10 production depending on the stimulation used. Genes Immun. 5: 246-255.

Pissetti CW, Bianco TM, Tanaka SC, Nascentes GA, et al. (2014). Protective role of the G allele of the polymorphism in the Interleukin 10 gene (-1082G/A) against the development of preeclampsia. Rev. Bras. Ginecol. Obstet. 36: 456-460.

Pontillo A, Reis EC, Bricher PN, Vianna P, et al (2015). NLRP1 L155H polymorphism is a risk factor for preeclampsia development. Am. J. Reprod. Immunol. 73: 577-581.

Redman CW and Sargent IL (2005). Latest advances in understanding preeclampsia. Science 308: 1592-1594.

Sibai B, Dekker G and Kupferminc M (2005). Pre-eclampsia. Lancet 365: 785-799.

Sowmya S, Ramaiah A, Sunitha T, Nallari P, et al. (2014a). Role of IL-10 -819(t/c) promoter polymorphism in preeclampsia. Inflammation 37: 1022-1027.

Sowmya S, Sri Manjari K, Ramaiah A, Sunitha T, et al. (2014b). Interleukin 10 gene promoter polymorphisms in women with early-onset pre-eclampsia. Clin. Exp. Immunol. 178: 334-341.

Sowmya S, Ramaiah A, Nallari P, Jyothy A, et al. (2015). Role of IL-6 -174(G/C) promoter polymorphism in the etiology of earlyonset preeclampsia. Inflamm. Res. 64: 433-439.

Stonek F, Hafner E, Metzenbauer M, Katharina S, et al. (2008). Absence of an association of tumor necrosis factor (TNF)-alpha G308A, interleukin-6 (IL-6) G174C and interleukin-10 (IL-10) G1082A polymorphism in women with preeclampsia. J. Reprod. Immunol. 77: 85-90.

Vural P, Degirmencioglu S, Saral NY, Demirkan A, et al. (2010). Tumor necrosis factor alpha, interleukin-6 and interleukin-10 polymorphisms in preeclampsia. J. Obstet. Gynaecol. Res. 36: 64-71.

Wang JX, Knottnerus AM, Schuit G, Norman RJ, et al. (2002). Surgically obtained sperm, and risk of gestational hypertension and pre-eclampsia. Lancet 359: 673-674.

Wang X, Jiang F, Liang Y, Xu L, et al. (2014). Interleukin-1ß-31C/T and -511T/C polymorphisms were associated with preeclampsia in Chinese Han population. PLoS One 9: e106919.

Wu X, Yang K, Tang X, Sa Y, et al. (2015). Folate metabolism gene polymorphisms MTHFR C677T and A1298C and risk for preeclampsia: a meta-analysis. J. Assist. Reprod. Genet. 32: 797-805.

Yang W, Zhu Z, Wang J, Ye W, et al. (2014). Evaluation of association of maternal IL-10 polymorphisms with risk of preeclampsia by a meta-analysis. J. Cell Mol. Med. 18: 2466-2477. 